\title{
Improved access to life insurance after genetic diagnosis of familial hypercholesterolaemia: cross-sectional postal questionnaire study
}

\author{
Roeland Huijgen $^{1}$, Sietske JM Homsma ${ }^{1}$, Barbara A Hutten ${ }^{2}$, Iris Kindt ${ }^{3}$, Maud N Vissers ${ }^{1}$, John JP Kastelein ${ }^{1}$ \\ and Jan LA van Rijckevorsel ${ }^{\star, 4}$
}

A decade ago, in the initial stage of genetic testing for familial hypercholesterolaemia (FH) in The Netherlands, it was reported that such screening decreased access to affordable life insurance for mutation carriers. In 2003, in order to improve access to insurance for FH mutation carriers, insurers agreed to underwrite according to a set of guidelines. In this cross-sectional study, we assessed whether access to insurance has improved since the advent of these guidelines. We approached 2825 subjects that had participated in the genetic testing for FH between 1998 and 2003. We compared unconditional acceptance rates before and after FH diagnosis and before and after the guidelines were issued by means of logistic regression analysis. Our study outcome pertains to $414 \mathrm{FH}$ patients who applied for life insurance. Unconditional acceptance of a policy before DNA diagnosis and before the issue of guidelines occurred in 182 out of $255(71 \%)$ cases, versus 27 out of $35(77 \%)$ cases after DNA diagnosis, but before the issue of guidelines. De facto, 107 out of $124(86 \%)$ patients received unconditional acceptance after DNA diagnosis and after the issue of guidelines $(P$ for trend=0.002). Access to life insurance improved for $\mathrm{FH}$ patients after molecular diagnosis and it improved even further after the guidelines were issued. Therefore, we argue that limited access to life insurance on the basis of 'DNA discrimination' is no longer a valid argument against genetic cascade testing for $\mathrm{FH}$, at least not in our country.

European Journal of Human Genetics (2012) 20, 722-728; doi:10.1038/ejhg.2012.5; published online 1 February 2012

Keywords: familial hypercholesterolemia; hyperlipoproteinemia Type II; genetic testing; genetic testing and adverse effects; life insurance

\section{INTRODUCTION}

The number of heritable disorders for which a genetic test is available increased from less than 200 in 1993 to more than 1800 in $2009 .{ }^{1}$ DNA diagnostics of a medical condition offers the possibility to start treatment before the disease becomes symptomatic. One of the possible downsides of genetic testing is that a person's test result may affect one's ability to obtain life insurance.

Familial hypercholesterolaemia $(\mathrm{FH})$ is a condition that meets key criteria for genetic testing. ${ }^{2}$ It is a prevalent inherited disorder of lipoprotein metabolism characterized by markedly elevated lowdensity lipoprotein (LDL-) cholesterol levels and premature coronary artery disease $(\mathrm{CAD}) .^{3}$ Cholesterol-lowering treatment has been shown to dramatically reduce $\mathrm{CAD}$ risk in patients with $\mathrm{FH}$ and, as a consequence, early identification by genetic testing for $\mathrm{FH}$ followed by effective treatment can reduce the incidence of CAD events substantially. ${ }^{4,5}$

A publication from 2002 reported, however, that subjects might have impaired access to insurance in the Netherlands after genetic FH diagnosis. ${ }^{6}$ On the basis of these findings, our government requested the Association of Insurers to settle these issues with the patient organisation, screening organisation and representatives of the medical profession. Accordingly, they reached agreement in 2003 and, as a result, insurers agreed to underwrite according to a set of specific guidelines. These guidelines stipulate that subjects with genetic $\mathrm{FH}$ and free of cardiovascular disease should be offered an unconditional life insurance policy under most conditions. ${ }^{7}$ The main requirements were that individuals had LDL-cholesterol levels, either treated or untreated, at or below $4.0 \mathrm{mmol} / \mathrm{l}$ although other cardiovascular risk factors, such as smoking, hypertension, diabetes or obesity, had to be absent at the time of life insurance application. The effect of these guidelines on access to life insurance for $\mathrm{FH}$ patients had never been evaluated.

The purpose of this study is therefore to assess whether FH diagnosis through genetic testing reduced access to life insurance and whether that access improved for subjects with $\mathrm{FH}$ after the guidelines were issued.

In the present study, we determined the access to insurance in a large cohort that had been tested for genetic FH. Here, we present our results.

\section{METHODS}

Recruitment

Individuals that had participated in the genetic cascade-screening programme for FH in the Netherlands between January 1998 and June 2003 were eligible for

${ }^{1}$ Department of Vascular Medicine, Academic Medical Center, University of Amsterdam, Amsterdam, The Netherlands; ${ }^{2}$ Department of Clinical Epidemiology, Biostatistics and Bioinformatics, Academic Medical Center, University of Amsterdam, Amsterdam, The Netherlands; ${ }^{3}$ Foundation for Identification of Persons with Inherited Hypercholesterolemia, Amsterdam, The Netherlands; ${ }^{4}$ Department of Quantitative Economics, Amsterdam School of Economics, University of Amsterdam, Amsterdam, The Netherlands

${ }^{*}$ Correspondence: Professor JLA van Rijckevorsel, Department of Quantitative, Economics, Amsterdam School of Economics, University of Amsterdam, Valckenierstraat 65-67, 1018 XE Amsterdam, The Netherlands. E-mail: j.I.a.vanRijckevorsel@uva.nl

Received 10 October 2011; revised 22 December 2011; accepted 3 January 2012; published online 1 February 2012 
this cross-sectional postal questionnaire survey. We selected those subjects aged between 18 and 55 years in 2008, who had given written informed consent to be approached for scientific studies at the time of genetic testing for $\mathrm{FH}$. In order to include subjects with and without $\mathrm{FH}$ in a 2:1 ratio (see power calculation below), we approached all selected subjects with genetic $\mathrm{FH}$, whereas we randomly included only one out of three subjects shown not to carry the FH mutation running in their family.

The study was approved by the Medical Ethical Committee of the Academic Medical Center of the University of Amsterdam.

\section{Outcome measures}

The main study outcome was the unconditional acceptance rate for life insurance applications.

As all subjects were diagnosed before the guidelines were issued on July 1st 2003, there were three options for the moment of insurance application: before genetic $\mathrm{FH}$ diagnosis and before the insurance guidelines were launched (Period 1); before DNA diagnosis and before the guidelines were launched (Period 2); after DNA diagnosis and after the guidelines were launched (Period 3). For each period the unconditional acceptance rate was calculated and stratified for those with and without genetic FH.

Unconditional acceptance was defined as a life insurance application accepted at standard premium and coverage. Processing of the insurance application with additional terms to the contract - from hereon described as 'conditional acceptance' - consisted of: (i) refusal of the application by the insurance company; (ii) acceptance with the obligation to pay a higher premium; acceptance with altered terms of the contract, for example excluding coverage of death by coronary heart disease; or (iii) the applicant's refusal to accept a life insurance policy that would include a higher premium or a clause.

A secondary outcome was the proportion of conditional acceptance of life insurance applications that were unjustified according to the guidelines. The guidelines stipulated that non-normal acceptance was justified in case of LDLcholesterol levels above $4 \mathrm{mmol} / \mathrm{l}$ at the time of application, and/or if one or more of the other cardiovascular risk factors, that is diabetes, hypertension, smoking and obesity were present. ${ }^{7}$ We defined obesity as having a body mass index (BMI) above $30 \mathrm{~kg} / \mathrm{m}^{2}$. If the LDL-cholesterol level at the time of application for a life insurance was unknown, we estimated the LDL-cholesterol level based on the total cholesterol level. We presumed that LDL-cholesterol was above $4 \mathrm{mmol} / \mathrm{l}$ in cases where the total cholesterol was above $6 \mathrm{mmol} / \mathrm{l}$ at the time of application or - if total cholesterol level was also unknown at that time - if the highest ever total cholesterol was above $10 \mathrm{mmol} / \mathrm{l}$

\section{Data collection}

In order to estimate the response rate and to verify the clarity of the questions in the questionnaire, we sent a pilot mailing in January 2008 to the 500 subjects who had been diagnosed with $\mathrm{FH}$ most recently. As the questionnaire was not essentially changed based on the experience with the pilot mailings, we included the population from the pilot study in the overall study cohort. The remaining selected subjects were approached for the first time in September 2008. First, a letter explaining the purpose of this study was sent by surface mail with a return form for the participant to indicate whether or not he/she approved of participation (invitation mailing). If the subjects had approved, the questionnaire itself was sent by surface mail (questionnaire mailing). For the mailings that proved undeliverable, we contacted the Municipal Administration of the subjects' former address and attempted to retrieve their current address. Up to two additional mailings were sent to the subjects that did not respond to the invitation mailing within 2 months of delay. Similarly, we sent up to two reminders after 3 months to those who did not return the questionnaire. To assess the reasons for non-response, we called a subset of the group that did not respond to any of the three invitation mailings by telephone. For this purpose, all the non-responders from the pilot study cohort were approached and asked why they did not respond.

\section{Sample size calculation}

Under the assumptions that life insurance companies in general accept $97 \%$ of the applicants under normal condition ${ }^{8}$ and $85 \%$ of the $\mathrm{FH}$ patients free of CVD, we calculated that 141 subjects with $\mathrm{FH}$ and 71 without $\mathrm{FH}$, applying for a life insurance after July 2003, were required to detect a difference in acceptance of $12 \%$ with a power of $80 \%$ and 0.05 significance level (two-sided). On the basis of the response rate of a pilot mailing in 500 subjects with FH only (Supplementary Data File 1), we estimated that we had to approach $\sim 2700$ subjects.

\section{Statistical analysis}

Differences in continuous variables (age, total cholesterol and BMI) between subgroups were compared using the independent sample $t$-test. $\chi^{2}$-Tests were applied for comparing distributions of dichotomous data (gender, presence of hypertension or diabetes, smoking).

The unadjusted pair wise association between conditional acceptance of life insurance and clinical variables, such as age, sex, hypertension, diabetes, smoking, BMI, total cholesterol and FH mutation, was expressed by odds ratio's estimated by a series of bivariate logistic regression analyses. Subsequently, hierarchical multiple regression analysis with stepwise backward elimination was used to identify independent determinants of conditional acceptance. To handle the entries where the total cholesterol was missing, we assessed the association between total cholesterol and other potential explanatory variables with linear regression of the non-missing entries. Hereafter, the best predictors for total cholesterol were used to impute the missing values for total cholesterol based on nearest neighbour imputation. ${ }^{9}$ A two sided $P$-value $<0.05$ was considered significant. Statistical analyses were performed with SPSS for Windows, Rel 16.0.0, 2008 (SPSS Inc., Chicago, IL, USA) version 16.

\section{RESULTS}

\section{Recruitment and non-response}

In total, 6115 males and females aged between 18 and 55 years had participated in the genetic cascade-testing programme for $\mathrm{FH}$ between January 1998 and June 2003. Of these, 2558 carried the FH mutation and 3557 did not. Of the 6115 tested individuals, 2825 passed the additional selection steps and were sent an invitation letter. This population consisted of 1963 (69\%) subjects with genetic FH mutation and $862(31 \%)$ without $\mathrm{FH}$.

In total, 1192 (42\%) subjects did not respond to our invitation letter (Figure 1). Of the 1633 (58\%) subjects who responded, 1127 (69\%) did consent, $484(30 \%)$ did not consent for various reasons, and in 22 $(1 \%)$ cases, the invited subjects were deceased. All 1127 subjects that had consented were sent a questionnaire and 1040 (92\%) returned a completed questionnaire. The 1040 participants were on average 37 years of age at FH testing, and $527(50.7 \%)$ were male. Baseline demographic and clinical characteristics of patients with and without FH are summarised in Table 1. As expected, those patients with FH had higher untreated total cholesterol levels than those without $\mathrm{FH}$ $(P<0.001)$.

An extensive description and analysis of the groups of subjects that did not respond or did not consent is given in Supplementary Data File 1. In general, the clinical characteristics of the non-participants did not essentially differ from those of the 1040 participants (see Table 1 and Supplementary Data File 1).

\section{Life insurance}

Of the 1040 participants, 576 (55.4\%) had applied for life insurance, on average at the age of 33 . Of the 576 who had applied, $327(57 \%)$ were male and $249(43 \%)$ were female. Other clinical characteristics did not essentially differ between the participants that either had or had not applied for life insurance (data not shown).

\section{Unconditional acceptance rate of life insurance}

Of the 576 applicants for life insurance, 554 (96\%) were free of cardiovascular disease at the time of application (Figure 2). 


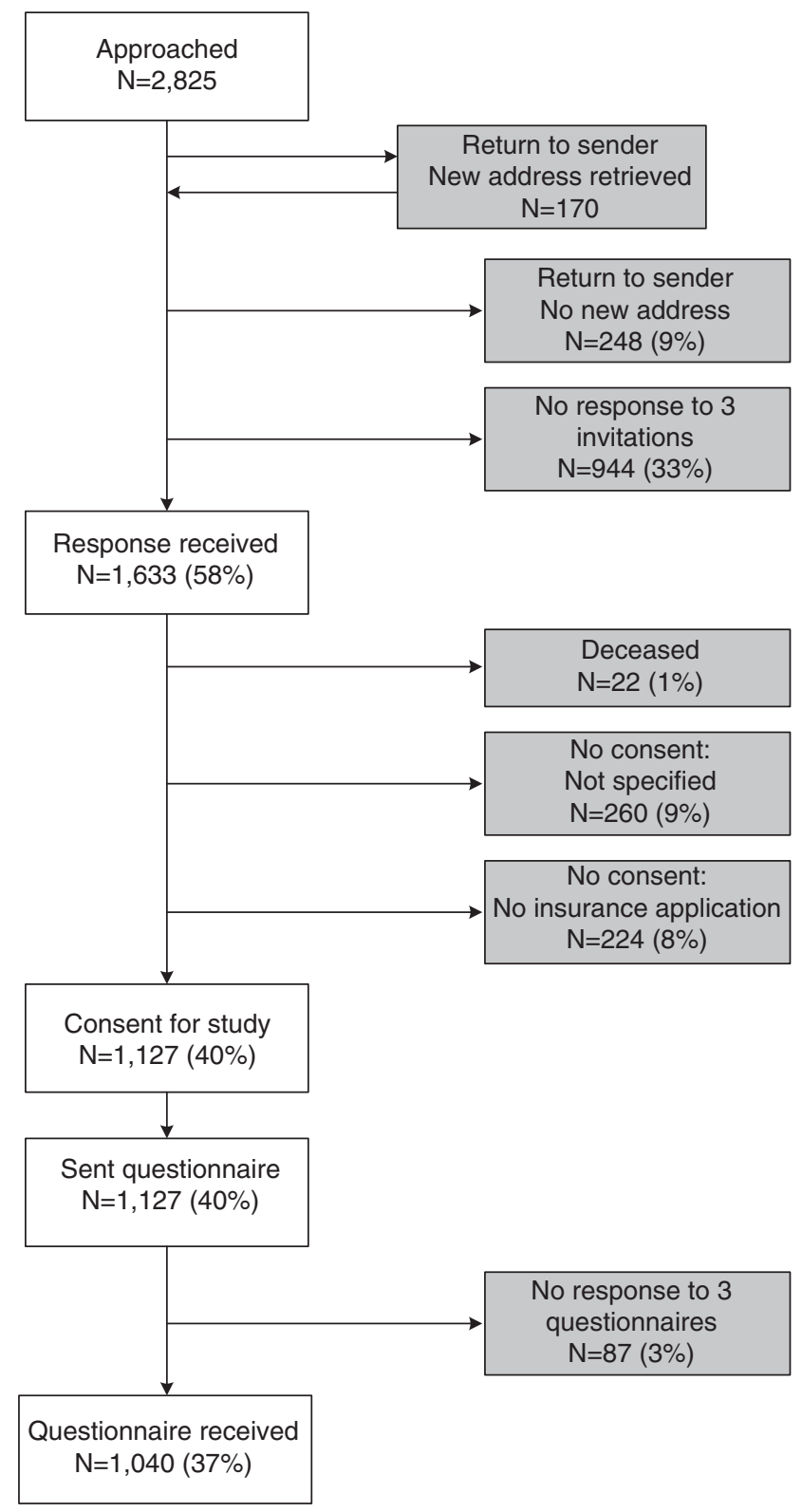

Figure 1 Flow diagram of the study.

Of those, 414 had FH: 255 had applied for a life insurance before genetic FH diagnosis (Period 1) of whom 182 (71.4\%) were accepted unconditionally, and a total of 159 subjects had applied for a life insurance after genetic FH diagnosis (Period 2 and 3 together) of whom $134(84.3 \%)$ were normally accepted. So, unconditional acceptance rate for $\mathrm{FH}$ patients improved statistically significantly from $71.4 \%$ before to $84.3 \%$ after genetic diagnosis $(P<0.001)$.

Among the 159 subjects who applied after genetic FH diagnosis, 35 subjects had applied before the guidelines were issued (Period 2) of whom $27(77.1 \%)$ were accepted unconditionally; 124 had applied after the guidelines were issued (Period 3), and of those, 107 (86.3\%) were accepted unconditionally. The overall unconditional acceptance rate in individuals with genetic $\mathrm{FH}$ improved significantly over the three periods, from $71.4 \%$ in Period 1 to $77.1 \%$ in Period 2 and to $86.3 \%$ in Period 3, with a $P$ for trend of 0.002 (Figure 3).
Subjects with conditional acceptance of the life insurance application

The life insurance applications of 17 individuals with genetic FH were conditionally accepted after the guidelines were issued in July 2003. No one was refused, $15(88 \%)$ were accepted under the condition that they had to pay a higher premium, one female (no. $2 ; 6 \%$ ) was accepted but cardiovascular mortality was excluded from coverage, and one female (no. 7; 6\%) refused to accept the life insurance because she had to pay a severely increased premium.

In general, these $17 \mathrm{FH}$ patients had a more adverse risk profile than the $107 \mathrm{FH}$ patients who were unconditionally accepted after the guidelines had been issued (Table 2 ). In fact, 11 of the 17 conditionally accepted subjects had total cholesterol levels before treatment and life style modifications above $10 \mathrm{mmol} / \mathrm{l}$ (65\%), compared with $13(25 \%)$ of those accepted unconditionally and whose highest total cholesterol 
level was known $(N=52)$. Of those accepted under specific conditions, $15(88 \%)$ had one or more risk factors that could justify conditional acceptance based on the guidelines (Table 2). We could not identify

Table 1 Demographic and clinical characteristics of the participants

\begin{tabular}{lccc}
\hline & $\begin{array}{c}\text { With } F H \\
\mathrm{n}=765\end{array}$ & $\begin{array}{c}\text { Without } \mathrm{FH} \\
\mathrm{n}=275\end{array}$ & P-value \\
\hline Male gender, $\mathrm{n}(\%)$ & $390(51)$ & $137(50)$ & 0.74 \\
Age years & $36.5 \pm 9.4$ & $38.4 \pm 8.9$ & 0.003 \\
Hypertension, $\mathrm{n}(\%)$ & $23(3)$ & $11(4)$ & 0.43 \\
Diabetes, $\mathrm{n}(\%)$ & $6(1)$ & $2(1)$ & 1 \\
Smoking, $\mathrm{n}(\%)$ & $198(29)$ & $70(27)$ & 0.59 \\
Highest total cholesterol $(\mathrm{mmol} / \mathrm{l})$ & $9.5 \pm 2.6$ & $5.5 \pm 1.4$ & $<0.001$ \\
Body mass index $\left(\mathrm{kg} / \mathrm{m}^{2}\right)$ & $24.2 \pm 3.6$ & $24.7 \pm 3.6$ & 0.07 \\
\hline
\end{tabular}

Abbreviation: $\mathrm{FH}$, familial hypercholesterolaemia.

Continuous variables were depicted as mean \pm SD .

apercentage based on all individuals for whom information on smoking status was available. any reason for conditional acceptance in the two remaining individuals (no. 2 and no. 12).

Of the 140 non-FH subjects who applied for life insurance, 138 (98.6\%) were accepted at normal premium (Figure 2). Only one 39 -year-old male $(2.2 \%)$ out of the 45 non-FH subjects, who applied for life insurance after the guidelines had been issued, had to pay a higher premium. While applying for life insurance, he had hypertension and he smoked. Overall, non-FH subjects were more often accepted unconditionally than subjects with $\mathrm{FH}$ when applying for life insurance after the guidelines had been issued $(97.8 \mathrm{vs}$ $86.4 \%, P=0.045)$.

Determinants of conditional acceptance of life insurance

Table 3 summarizes the association between conditional acceptance and several clinical variables for all 124 subjects with $\mathrm{FH}$ who had applied for life insurance since July 2003. Univariate odds ratio's show that BMI and total cholesterol were positively and statistically

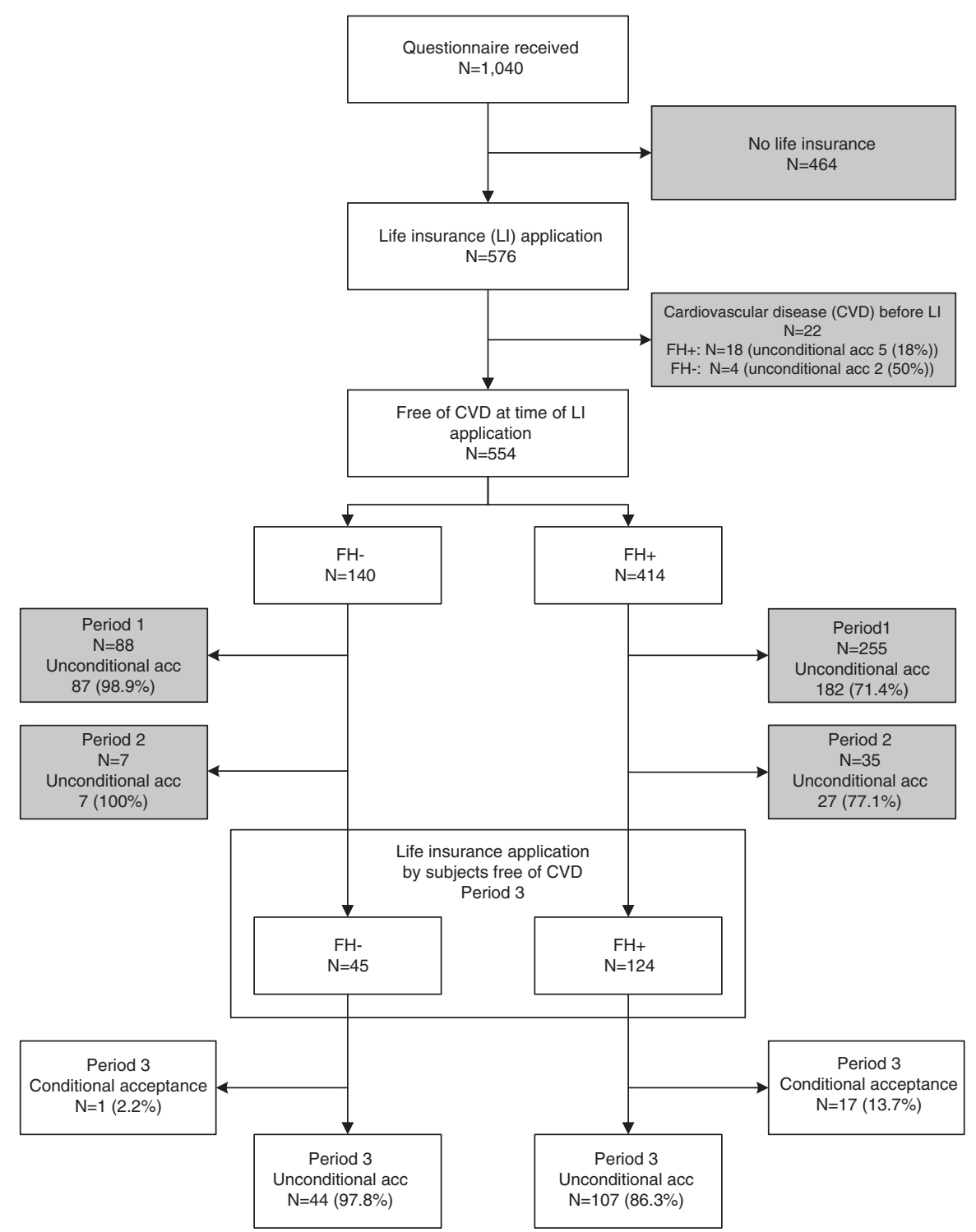

Figure 2 Flow diagram of participants that applied for life insurance. acc=acceptance, $C V D=$ cardiovascular disease, $F H=$ with genetic familial hypercholesterolaemia diagnosis, $\mathrm{LI}=$ life insurance, Period $1=$ Application before genetic $\mathrm{FH}$ test and before the guidelines were issued, Period $2=$ Application after genetic FH test and before the guidelines were issued, Period 3=Application after genetic FH test and after the guidelines were issued. 
significantly associated with conditional acceptance, while age, male gender and smoking showed a statistically non-significant trend. Using multiple regression analysis with stepwise backward elimination, total cholesterol was statistically significantly associated with conditional acceptance. BMI was significantly associated with conditional acceptance only in the model with all 124 subjects. Highest total cholesterol level was the only independent determinant that was statistical significantly associated with conditional acceptance, for patients with FH that had applied in periods 1 and 2 (OR 1.2, 95\% CI: 1.1 to $1.3 ; P=0.006$ ). Thus, the extent of dyslipidemia is an important determinant of conditional acceptance of life insurance applications, even among the subjects that carry an FH mutation and are aware of it.

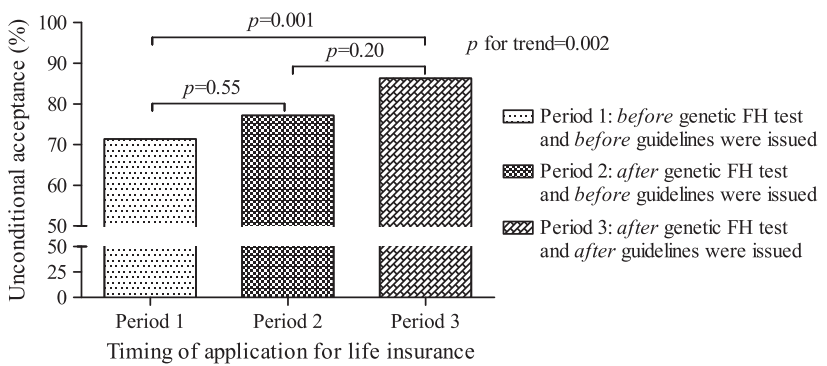

Figure 3 Unconditional acceptance rate of life insurance for subjects with genetic $\mathrm{FH}$. $\mathrm{FH}=$ familial hypercholesterolaemia. The number of applicants accepted under normal conditions and number of overall applicants were: 182 out of 255 in Period 1; 27 out of 35 in Period 2; and 107 out of 124 in Period 3.
Similarly, we performed regression analysis on the subjects both with and without FH who had applied for life insurance after the guidelines had been issued. Among these, 124 with and 45 without genetic $\mathrm{FH}$, the presence of hypertension, higher untreated total cholesterol levels and increased BMI were all statistically significantly associated with conditional acceptance in univariate analysis. In addition, FH mutation status was associated with a non-significant increased risk of conditional acceptance (OR 7.0, 95\% CI: 0.9 to $54 ; P=0.063$ ). In a multivariate backward model, which included total cholesterol levels, total cholesterol remained the only significant determinant of conditional acceptance (OR 1.6, 95\% CI: 1.2-2.1; $P=0.001$ ), whereas the association between $\mathrm{FH}$ mutation carriership and conditional acceptance was completely abolished $(P=0.99)$. Thus, the extent of hypercholesterolaemia appears to predominate over the presence or absence of FH genotype in determining conditional acceptance.

\section{DISCUSSION}

Our findings cautiously suggest that access to life insurance for individuals with genetic $\mathrm{FH}$ improved with the introduction of guidelines for insurers. Although the percentage of applicants without FH that obtain insurance on normal terms (98.6\%) is significantly greater than for applicants with genetic $\mathrm{FH}$, the vast majority $(86.3 \%)$ of FH patients are accepted without complications. As such, the unconditional acceptance for life insurance has much improved for patients with FH when compared with a decade ago. Nevertheless, individuals with genetic FH were accepted more often with additional conditions than those without genetic FH. This difference appeared to be determined to a greater extent by variations in cholesterol levels

Table 2 Characteristics of the FH subjects with conditional acceptance of life insurance (after the guidelines)

\begin{tabular}{|c|c|c|c|c|c|c|c|c|c|c|}
\hline Acceptance of $\mathrm{LI}$ & $\begin{array}{l}\text { Age at } L I \\
\text { mean } \pm S D\end{array}$ & $\begin{array}{l}\text { Male } \\
n(\%)\end{array}$ & $\begin{array}{l}H T n \\
(\%)\end{array}$ & $\begin{array}{c}D M n \\
(\%)\end{array}$ & $\begin{array}{c}\text { Smoking } \\
n(\%)\end{array}$ & $\begin{array}{c}B M I \\
\text { mean } \pm S D\end{array}$ & $\begin{array}{l}\text { Highest TC } \\
\text { mean } \pm S D\end{array}$ & Treated at $\mathrm{LI}$ & $T C$ at $\mathrm{LI}$ & $L D L-C^{\mathrm{a}} \leq 4 \mathrm{mmol} / \mathrm{l}$ at $\mathrm{LI}$ \\
\hline $\begin{array}{l}\text { Unconditional } \\
(N=107)\end{array}$ & $34 \pm 8$ & $56(52)$ & $0(0)$ & $0(0)$ & $23(22)$ & $23.2 \pm 3.2$ & $8.5 \pm 1.9$ & - & - & - \\
\hline $\begin{array}{l}\text { Conditional } \\
(N=17)\end{array}$ & $35 \pm 6$ & $12(71)$ & $1(6)$ & $1(6)$ & $6(35)$ & $25.2 \pm 4.6$ & $10.8 \pm 3.2$ & - & - & - \\
\hline
\end{tabular}

\begin{tabular}{|c|c|c|c|c|c|c|c|c|c|c|}
\hline No. $1=41$ & 35 & Male & No & No & No & 26.5 & 12 & Yes, statin (unspecified) & 6 & Unknown, TC with treatment 6.0 \\
\hline No. $2=103$ & 37 & Female & No & No & No & 21.2 & 10 & Yes, atorvastatin $40 \mathrm{mg}$ & 4.8 & Yes, TC with treatment 4.8 \\
\hline No. $3=141$ & 35 & Male & No & No & Yes & 22.4 & 12.9 & Yes, statin (unspecified) & 8.5 & No, TC with treatment 8.5 \\
\hline No. $4=170$ & 28 & Male & No & No & Yes & 21.5 & 13 & Yes, atorvastatin $40 \mathrm{mg}$ & 7.2 & No, TC with treatment 7.2 \\
\hline No. $5=195$ & 47 & Male & No & Yes & No & 34.3 & 11 & Yes, statin (unspecified) & 7 & No, TC with treatment 7.0 \\
\hline No. $6=578$ & 34 & Male & No & No & No & 21.9 & 13 & Yes, atorvastatin $40 \mathrm{mg}$ & 7 & No, TC with treatment 7.0 \\
\hline No. $7=625$ & 31 & Female & No & No & No & 21.6 & 19 & Yes, LDL-apherese & $>6$ & No, TC with treatment $>6$ \\
\hline No. $8=1015$ & 36 & Male & No & No & Yes & 27 & 9 & $\begin{array}{l}\text { Yes, atorvastatin } 40 \mathrm{mg} \\
\text { and ezetimibe } 10 \mathrm{mg}\end{array}$ & 5.5 & Yes, TC with treatment 5.5 \\
\hline No. $9=1301$ & 23 & Female & No & No & Yes & 29.4 & 7.4 & Yes, simvastatin $20 \mathrm{mg}$ & 5 & Yes, TC with treatment 5 \\
\hline No. $10=1372$ & 37 & Male & No & No & No & 24.8 & 13.6 & Yes, simvastatin $20 \mathrm{mg}$ & 6.5 & No, TC with treatment 6.5 \\
\hline No. $11=3055$ & 35 & Female & Yes & No & No & 20 & 11 & Yes, atorvastatin $20 \mathrm{mg}$ & 4.2 & Yes, TC with treatment 4.2 \\
\hline No. $12=3059$ & 32 & Female & No & No & No & 23.9 & 8.6 & $\begin{array}{l}\text { Yes, atorvastatin } 40 \mathrm{mg} \\
\text { and ezetimibe } 10 \mathrm{mg} .\end{array}$ & 4 & Yes, TC with treatment 4.0 \\
\hline No. $13=3075$ & 34 & Male & No & No & No & 33.6 & 10.5 & Yes, rosuvastatin $20 \mathrm{mg}$ & 7 & No, LDL-C with treatment 5.5 \\
\hline No. $14=3225$ & 49 & Male & No & No & No & 31.7 & 12 & No & 12 & No, no treatment with high TC \\
\hline No. $15=3497$ & 41 & Male & No & No & Yes & 20.8 & 7.3 & Yes, statin (unspecified) & $<6$ & Yes, TC with treatment $<6$ \\
\hline No. $16=3506$ & 36 & Male & No & No & No & 26.9 & 5.6 & No & $<6$ & No, LDL-C $=4.1$ at application LI \\
\hline No. $17=3518$ & 30 & Male & No & No & Yes & 21.7 & 7.5 & Yes, statin (unspecified) & $<6$ & Yes, TC with treatment $<6$ \\
\hline
\end{tabular}

Abbreviations: BMI, body mass index; DM, diabetes mellitus; FH, familial hypercholesterolaemia; HT, hypertension; LDL-C, low-density lipoprotein cholesterol; LI, life insurance application; mg, milligram; SD, standard deviation; TC, total cholesterol.

Depicted are the cardiovascular risk factors for the subjects with FH that had applied for a life insurance after the guidelines were issued.

aLDL-cholesterol level if it was known at the time of application or, if unknown, an estimate of whether LDL-cholesterol would be $\leq 4.0 \mathrm{mmol} / \mathrm{l}$ or not based on known total cholesterol levels. 
Table 3 Determinants of conditional acceptance for life insurance after the guidelines for the subjects with FH

\begin{tabular}{lccccc}
\hline & Univariate OR $(95 \% \mathrm{Cl})$ & P-value & Model 1 $(\mathrm{n}=124)$ OR $(95 \% \mathrm{Cl})$ & P-value & Model 2(n=69) OR (95\% Cl) \\
\hline Age at application (years) & $1.02(0.96-1.09)$ & 0.51 & - & - & - \\
Male (gender) & $2.19(0.72-6.63)$ & 0.17 & - & - & - \\
Smoking & $2.07(0.73-5.90)$ & 0.17 & $1.16(1.00-1.35)$ & - & - \\
Body mass index $\left(\mathrm{kg} / \mathrm{m}^{2}\right)$ & $1.16(1.02-1.33)$ & 0.028 & $1.74(1.27-2.37)$ & $<0.001$ & - \\
Total cholesterol $(\mathrm{mmol} / \mathrm{l})$ & $1.49(1.13-1.95)$ & 0.005 & - & - \\
\hline
\end{tabular}

Abbreviations: $\mathrm{FH}$, familial hypercholesterolaemia; OR, odds ratio; Total cholesterol, highest level of total cholesterol measured ever; $95 \% \mathrm{Cl}$, 95\% confidence interval.

Model 1 and 2 resulted from a multiple regression analysis based on stepwise backward elimination with age, sex, smoking, body mass index and total cholesterol as independent variables. For model 1 missing values for total cholesterol and smoking were imputed. For model 2, only those subjects were included for whom all variables in the model were known, which was applicable for $69(56 \%)$ of the 124 subjects.

than by mutation carriership. Thus, access to life insurance depends more on the actual phenotype of $\mathrm{FH}$ than on the genotype.

The findings of a survey that also focussed on life insurance after $\mathrm{FH}$ diagnosis in the Netherlands were published in $2002 .{ }^{6}$ In that study 46 subjects had applied for life insurance in the period between genetic FH diagnosis and the time of the survey. Of those 46 individuals, 17 (37\%) had experienced a broad range of problems with their life insurance application. These problems included outright refusal of the application and conditional acceptance. In that study with its limited sample size, the acceptance of life insurance applications before FH diagnosis was not evaluated. Nevertheless, the authors concluded that patients with $\mathrm{FH}$ encountered unanticipated insurance problems as a result of participating in the genetic testing programme.

In contrast, our findings suggest that the genetic FH diagnosis itself did not result in the failure to obtain life insurance on normal terms. In fact, in our genetic FH cohort the unconditional acceptance of life insurance improved significantly from $71.4 \%$ before molecular diagnosis to $84.3 \%$ after $\mathrm{FH}$ was identified.

Furthermore, unconditional acceptance of life insurance applications for the cohort with genetic FH increased in successive periods. It is difficult to interpret, however, whether the improvement in access to life insurance after $\mathrm{FH}$ diagnosis was primarily attributable to a beneficial effect of the guidelines. In this respect, the elegant studies by Neil and colleagues are of interest. ${ }^{10,11}$ They performed a survey with life insurance applications by fictional FH patients among 41 insurance companies underwriting life insurance in the United Kingdom in 1990 and repeated the study among 26 of these companies in 2002. They observed that insurance companies applied a much lower excess mortality rating for $\mathrm{FH}$ patients taking statins in 2002 than for the untreated $\mathrm{FH}$ patients in 1990, which indicated that insurers recognize that the prognosis of $\mathrm{FH}$ patients has improved with more effective treatment. Similarly, the awareness among Dutch insurers of the improved prognosis of treated $\mathrm{FH}$ patients made it possible to reach agreement and introduce the guidelines in $2003 .{ }^{7}$ Since then, several findings have been published, which show that the prognosis for treated FH patients has improved in the post statin era. ${ }^{5,12}$ These findings may have influenced decision-making among insurers underwriting life insurance even further. Thus, whether improvement in acceptance rate over time is owing to the guidelines or to awareness of improved prognosis of treated $\mathrm{FH}$ patients remains difficult to determine. One indication that the guidelines were indeed important was that insurance companies generally adhere to the guidelines. In fact, the vast majority (86.6\%) of applicants with FH were accepted unconditionally, and only two of the $17(12 \%)$ conditional acceptances after 2003 could be considered a deviation from the guidelines by the insurers.

Untreated FH patients are at severely increased risk of cardiovascular death at a young age. ${ }^{13}$ In addition, those with pathogenic mutations that result in higher LDL-cholesterol levels have shorter coronary heart disease event free survival than the somewhat milder FH mutations. ${ }^{14}$ The guidelines for insurers were designed based on that knowledge. Consequently, applicants with $\mathrm{FH}$ were required to have LDL-C levels below $4 \mathrm{mmol} / \mathrm{l}$ in order to be applicable for unconditional acceptance. In our study cohort, several FH patients applied for life insurance although LDL-C levels were above $4 \mathrm{mmol} / \mathrm{l}$ at that time. Among the 17 individuals with $\mathrm{FH}$ who were accepted with additional conditions after July 2003, at least 8 had levels above $4 \mathrm{mmol} / \mathrm{l}$. As such, high cholesterol levels proved an important predictor of conditional acceptance.

Of note, in current clinical practice a considerable subset of $\mathrm{FH}$ patients does not succeed in achieving LDL-C levels below $4 \mathrm{mmol} / \mathrm{l}$. In a large survey among 1249 patients that attended outpatient lipid clinics in the Netherlands for more than a year, we observed that only $81 \%$ of those achieved LDL-C levels below $4 \mathrm{mmol} / \mathrm{l} .{ }^{15}$ Similarly, a survey among 781 subjects who had been diagnosed by the screening programme with genetic $\mathrm{FH}$ in 2006 showed that in 2008 only 612 (78.4\%) had achieved LDL-C levels below $4 \mathrm{mmol} / 1 .{ }^{16}$ Thus, for some FH patients and physicians the target level stipulated for access to insurance could work as an additional incentive to treat to lower cholesterol levels. But for several others the target level may be discouraging, because it is unachievable for them with currently available treatment options. Even when treated with potent regimens, such patients still present insurance (ie, actuarial) risk for insurers. Companies underwriting life insurance are private corporations that are not obliged to accept every applicant. Whether insurance companies should make an exception and offer treated FH patients normal access to insurance regardless of their cholesterol levels is beyond the scope of the current article.

One strength of this study is that the patients and control participants were recruited from a clearly defined cohort, that is the individuals derived from families harbouring an $\mathrm{FH}$ mutation and therefore visited for genetic testing. In addition, we were able to include data of more than 500 individuals that applied for life insurance. However, a potential limitation was non-response. Response rate in this kind of study is lower than in research conducted in a clinical setting and questions about privacy related issues such as health and mortgage may be perceived as sensitive. Bias arises when non-response in a survey is related to the outcome being measured. We assessed the reasons for non-response and non-participation extensively, as described in Supplementary Data File 1. We identified several reasons for non-response. These reasons in general did not have an impact on the validity of the outcomes, which was confirmed by the reported reasons for non-response, which we obtained when we contacted a large subset of individuals that had not responded to the surface mails by telephone.

In conclusion, agreement between insurers and other parties in society to avoid genetic discrimination has proven a viable strategy to 
improve access to insurances for pre-symptomatic subjects with genetic FH. Accordingly, our findings may also encourage health care workers in other countries to reach similar settlements with insurance companies. Such an approach may also be applied to other treatable genetic conditions in which patient concerns about insurance discourage being tested. ${ }^{17,18}$ Whether the Dutch approach can be extrapolated to other countries, however, also depends, to some extent on country-specific legislation regarding genetic tests. ${ }^{19,20}$

If our findings are communicated to individuals from families harbouring an $\mathrm{FH}$ mutation, this may reduce the perception of discrimination based on genetic FH. It may enhance the participation rate in the screening programme for $\mathrm{FH}$, because it may encourage relatives to be tested, rather than being deterred by concerns about life insurance.

\section{CONFLICT OF INTEREST}

Roeland Huijgen, Barbara A Hutten, Maud N Vissers, John JP Kastelein and Jan LA van Rijckevorsel declare no conflict of interest. Sietske JM Homsma was employed by the Dutch Association of Insurers at the time we conducted this study. Iris Kindt is the director of the cascade-screening organization for familial hypercholesterolemia in the Netherlands.

\section{ACKNOWLEDGEMENTS}

This study was funded by the Dutch Association of Insurers.

1 Beaudet AL: Which way for genetic-test regulation? Leave test interpretation to specialists. Nature 2010; 466: 816-817.

2 Wilson JM, Jungner YG: Principles and practice of mass screening for disease. Bol Oficina Sanit Panam 1968; 65: 281-393.

3 Goldstein JL, Hobbs HH, Brown MS: The Metabolic and Molecular Bases of Inherited Disease. McGraw-Hill: New York, 2001.
4 Huijgen R, Vissers MN, Defesche JC, Lansberg PJ, Kastelein JJ, Hutten BA: Familial hypercholesterolemia: current treatment and advances in management. Expert Rev Cardiovasc Ther 2008; 6: 567-581.

5 Versmissen J, Oosterveer DM, Yazdanpanah M et al: Efficacy of statins in familial hypercholesterolaemia: a long term cohort study. BMJ 2008; 337: a2423.

6 Marang-van de Mheen PJ, van Maarle MC, Stouthard ME: Getting insurance after genetic screening on familial hypercholesterolaemia; the need to educate both insurers and the public to increase adherence to national guidelines in The Netherlands. J Epidemiol Community Health 2002; 56: 145-147.

7 Homsma SJ, Huijgen R, Middeldorp S, Sijbrands EJ, Kastelein JJ: Molecular screening for familial hypercholesterolaemia: consequences for life and disability insurance. Eur $J$ Hum Genet 2008; 16: 14-17.

8 Sijbrands EJ, Tornij E, Homsma SJ: Mortality risk prediction by an insurance company and long-term follow-up of 62,000 men. PLOS ONE 2009; 4: e5457.

9 Rancourt E: Estimation with Nearest-Neighbour Imputation at Statistics Canada; in: American Statistical Association (ed): Proceedings of the Survey Research Methods Section, 1999, PP 131-138.

10 Neil HA, Mant D: Cholesterol screening and life assurance. BMJ 1991; 302: 891-893.

11 Neil HA, Hammond T, Mant D, Humphries SE: Effect of statin treatment for familial hypercholesterolaemia on life assurance: results of consecutive surveys in 1990 and 2002. BMJ 2004; 328: 500-501.

12 Neil A, Cooper J, Betteridge J et al: Reductions in all-cause, cancer, and coronary mortality in statin-treated patients with heterozygous familial hypercholesterolaemia: a prospective registry study. Eur Heart J 2008; 29: 2625-2633.

13 Slack J: Risks of ischaemic heart-disease in familial hyperlipoproteinaemic states. Lancet 1969; 2: 1380-1382.

14 Umans-Eckenhausen MA, Sijbrands EJ, Kastelein JJ, Defesche JC: Low-density lipoprotein receptor gene mutations and cardiovascular risk in a large genetic cascade screening population. Circulation 2002; 106: 3031-3036.

15 Pijlman AH, Huijgen R, Verhagen SN et al: Evaluation of cholesterol lowering treatment of patients with familial hypercholesterolemia: a large cross-sectional study in The Netherlands. Atherosclerosis 2010; 209: 189-194.

16 Huijgen R, Kindt I, Verhoeven SB et al: Two years after molecular diagnosis of familial hypercholesterolemia: majority on cholesterol-lowering treatment but a minority reaches treatment goal. PLOS ONE 2010; 5: e9220.

17 Phatak PD, Bonkovsky HL, Kowdley KV: Hereditary hemochromatosis: time for targeted screening. Ann Intern Med 2008; 149: 270-272.

18 Low L, King S, Wilkie T: Genetic discrimination in life insurance: empirical evidence from a cross sectional survey of genetic support groups in the United Kingdom. BMJ 1998; 317: 1632-1635.

19 Josefson D: Clinton outlaws genetic discrimination in federal jobs. BMJ 2000; 320: 468.

20 Morrison PJ: Implications of genetic testing for insurance in the UK. Lancet 1998; 352: $1647-1648$.

Supplementary Information accompanies the paper on European Journal of Human Genetics website (http://www.nature.com/ejhg) 